\title{
Midwifery care, social and medical risk factors, and birth outcomes in the USA
}

\author{
Marian F MacDorman, Gopal K Singh
}

\begin{abstract}
Study objective-To determine if there are significant differences in birth outcomes and survival for infants delivered by certified nurse midwives compared with those delivered by physicians, and whether these differences, if they exist, remain after controlling for sociodemographic and medical risk factors.

Design-Logistic regression models were used to examine differences between certified nurse midwife and physician delivered births in infant, neonatal, and postneonatal mortality, and risk of low birthweight after controlling for a variety of social and medical risk factors. Ordinary least squares regression models were used to examine differences in mean birthweight after controlling for the same risk factors.
\end{abstract}

Study setting-United States.

Patients-The study included all singleton, vaginal births at 35-43 weeks gestation delivered either by physicians or certified nurse midwives in the United States in 1991.

Main results-After controlling for social and medical risk factors, the risk of experiencing an infant death was $19 \%$ lower for certified nurse midwife attended than for physician attended births, the risk of neonatal mortality was $33 \%$ lower, and the risk of delivering a low birthweight infant 31\% lower. Mean birthweight was 37 grams heavier for the certified nurse midwife attended than for physician attended births.

Conclusions-National data support the findings of previous local studies that certified nurse midwives have excellent birth outcomes. These findings are discussed in light of differences between certified nurse midwives and physicians in prenatal care and labour and delivery care practices. Certified nurse midwives provide a safe and viable alternative to maternity care in the United States, particularly for low to moderate risk women.

(F Epidemiol Community Health 1998;52:310-317)

Currently the United States ranks 22 nd in the world in infant mortality, behind such other countries as Japan, Singapore, Finland, Sweden, and Switzerland. In 1992, the infant mortality rate for number one ranked Japan was 4.5 infant deaths per 1000 live births, nearly half the rate of 8.5 for the United States. ${ }^{1}$

Despite skyrocketing health care expenditures for obstetric and neonatal care (estimated at $\$ 26.5$ billion in $1987,{ }^{2}$ up from $\$ 16$ billion in $1985^{3}$ ), numerous barriers in access to prenatal and perinatal care still exist for many pregnant women. ${ }^{3-5}$ This is reflected in the fact that only $76 \%$ of women in 1991 began prenatal care in the first trimester, a proportion that had been essentially unchanged since $1979 .{ }^{6}$ This proportion increased to $80 \%$ in $1994 .^{7}$ Many studies have focused on ways to reduce the infant mortality rate in the US while controlling costs, expanding coverage, and improving the quality of prenatal and perinatal care..$^{2-589}$

A number of studies have advocated the increased involvement of midwives in US maternity care, as women whose pregnancies are managed by midwives generally receive excellent care with lower rates of costly medical interventions such as caesarean section, vacuum and forceps deliveries, induction of labour, ultrasound, and continuous fetal monitoring. ${ }^{20-17}$ The number of births delivered by midwives has increased rapidly in recent years, from $29413(0.9 \%)$ in $1975^{18}{ }^{19}$ to 182461 (4.4\%) in 1991 and 218466 (5.5\%) in $1994 .{ }^{6}{ }^{7}$ Of these births the per cent born in hospital has increased from $67 \%$ in 1975 to $88 \%$ in 1991 and $90 \%$ in 1994 . For certified nurse midwives, the proportion is even higher-more than $94 \%$ of all certified nurse midwife delivered births in 1991 were born in hospitals (95\% in 1994). With increased hospital privileges and more active collaborative arrangements with physicians, certified nurse midwives have been able to offer their services to a more diverse group of women. A recent national study has demonstrated that the overall risk profile for births delivered by certified nurse midwives in hospital is similar to the risk profile for physician delivered hospital births. ${ }^{20}$ In addition, certified nurse midwives tend to handle a higher proportion of women in certain sociodemographic risk categories, such as teenage mothers, those living in poverty, women who have not completed high school, and ethnic minorities. ${ }^{20-23}$

This study compares birth outcomes and infant mortality rates for births in the United States delivered by physicians (MDs and DOs) and certified nurse midwives. Births delivered by other midwives are excluded because of the small percentage of overall births $(0.4 \%)$, and also because of the diverse backgrounds and training of midwives in this group caused in part by large variations in state law regarding the training and licensing of other midwives. ${ }^{24}$ The purpose of this study is to examine whether there are significant differences in birth outcomes for infants delivered by certified nurse midwives compared with those 
Table 1 Characteristics of physician and certified nurse midwife delivered births: United States, 1991

\begin{tabular}{|c|c|c|c|c|}
\hline & \multicolumn{2}{|l|}{ All deliveries } & \multicolumn{2}{|c|}{$\begin{array}{l}\text { Singleton, vaginal deliveries } 35-43 \\
\text { weeks gestation }\end{array}$} \\
\hline & Physician & Certified nurse midwife & Physician & $\begin{array}{l}\text { Certified nurse } \\
\text { midwife }\end{array}$ \\
\hline Number of births & 3892192 & 167706 & 2634550 & 153194 \\
\hline Per cent of total births $\star$ & 94.7 & 4.1 & 93.2 & 5.4 \\
\hline Infant mortality rate $†$ & 8.8 & 4.1 & 3.6 & 3.1 \\
\hline Neonatal mortality rate $\nmid$ & 5.6 & 1.6 & 1.2 & 0.8 \\
\hline Postneonatal mortality rate ${ }^{\prime}$ & 3.2 & 2.5 & 2.4 & 2.3 \\
\hline Low birthweight $(<2500 \mathrm{~g})(\%)$ & 7.3 & 3.2 & 3.5 & 2.5 \\
\hline Mean birthweight & 3333 & 3404 & 3390 & 3416 \\
\hline Preterm birth (\%) & 11.0 & 7.2 & 6.0 & 5.0 \\
\hline Mean weeks of gestation & 39.1 & 39.5 & 39.4 & 39.5 \\
\hline Delivered in hospital (\%) & 99.7 & 94.3 & 99.6 & 94.1 \\
\hline Single births $(\%)$ & 97.5 & 99.6 & 100.0 & 100.0 \\
\hline \multicolumn{5}{|l|}{ Vaginal deliveries (includes vaginal births } \\
\hline after caesarean section) $(\%)$ & 76.2 & $99.4 \dagger$ & 100.0 & 100.0 \\
\hline Non-Hispanic white (\%) & 64.5 & 51.4 & 65.3 & 52.0 \\
\hline Non-Hispanic black (\%) & 16.3 & 18.8 & 15.5 & 18.4 \\
\hline Asian and Pacific Islander (\%) & 3.5 & 3.7 & 3.7 & 3.7 \\
\hline American Indian (\%) & 0.9 & 3.1 & 0.9 & 3.1 \\
\hline Hispanic (\%) & 14.9 & 23.1 & 14.8 & 23.0 \\
\hline Maternal age $<20$ years $(\%)$ & 12.7 & 17.2 & 13.3 & 16.9 \\
\hline Maternal age $35+$ years $(\%)$ & 9.4 & 8.3 & 8.6 & 8.5 \\
\hline Birth order $4+(\%)$ & 10.4 & 12.9 & 10.7 & 12.8 \\
\hline Unmarried (\%) & 29.1 & 38.5 & 29.0 & 38.0 \\
\hline Smokers (\%) & 17.8 & 18.3 & 17.7 & 18.0 \\
\hline Maternal education $<12$ years $(\%)$ & 23.3 & 32.3 & 23.6 & 31.8 \\
\hline Maternal education $16+$ years $(\%)$ & 18.3 & 14.3 & 18.4 & 14.8 \\
\hline \multicolumn{5}{|l|}{ Prenatal care began in 2 nd or 3 rd trimester } \\
\hline$(\%)$ or no care & 23.1 & 34.2 & 23.1 & 33.4 \\
\hline No prenatal care (\%) & 1.8 & 2.2 & 1.7 & 2.0 \\
\hline \multicolumn{5}{|l|}{ Medical risk factors/delivery complications } \\
\hline Abruptio placenta (\%) & 0.6 & 0.2 & 0.2 & 0.1 \\
\hline Breech/malpresentation (\%) & 4.0 & 0.4 & 0.5 & 0.3 \\
\hline Fetal distress (\%) & 4.4 & 1.7 & 2.1 & 1.6 \\
\hline Hydramnios/oligohydramnios & 0.7 & 0.5 & 0.5 & 0.5 \\
\hline Precipitous labour (<3 hours) (\%) & 1.8 & 2.8 & 2.2 & 2.8 \\
\hline Premature rupture of membrane ( $>12$ hours) $(\%)$ & 3.3 & 3.4 & 2.4 & 3.3 \\
\hline Seizures during labour (\%) & 0.04 & 0.02 & 0.02 & 0.02 \\
\hline
\end{tabular}

Missing data were excluded when computing percent distributions. Source: National Linked Birth/Infant Death data set, 1991 birth cohort. *An additional 51161 births or $1.2 \%$ of the total were delivered by attendants other than physicians and certified nurse midwives. These included other midwives $(0.4 \%)$, and other and unknown persons. †Rate per 1000 live births. $¥$ In 1991,959 births were reported with attendant at birth as certified nurse midwives and method of delivery as caesarean section. These probably refer to births where the initial attendant was a certified nurse midwife, but because of complications the birth had to be transferred to a physician to perform a caesarean section, and the attendant item on the birth certificate was not updated. As the multivariate analysis is limited to vaginal deliveries, the results of the study are not affected.

delivered by physicians, and whether these differences, if they exist, remain even after controlling for sociodemographic and medical risk factors.

\section{Methods}

DATA

This study uses data from the national linked birth/infant death data set for the 1991 birth cohort. In this data set, the death certificate is linked with the corresponding birth certificate for each infant who dies in the United States. The purpose of the linkage is to use the many additional variables available from the birth certificate in infant mortality analysis. Information on all of the approximately 4 million live births in the US each year is also included. For the 1991 birth cohort, $97.7 \%$ of US infant death certificates were successfully matched to their birth certificates. ${ }^{25}$

The descriptive analysis examines all US births as well as singleton, vaginal deliveries at 35-43 weeks gestation, to provide a comparison group between the US population as a whole, and the subset of this population used for the logistic and ordinary least squares (OLS) regression models. For the logistic and OLS regression models, the analysis was restricted to singleton, vaginal deliveries at 35-43 weeks gestation. As certified nurse midwives do not perform caesarean sections and perform fewer multiple deliveries than physicians (table 1), limiting the analysis to singleton, vaginal deliveries provided a more meaningful comparison of outcomes between physician and certified nurse midwife delivered births. A period of gestation of 35-43 weeks includes all term births as well as those \pm 2 weeks from term. Although midwifery protocols vary, in general women who present in labour at gestational ages remote from term are transferred to physician care. ${ }^{16}{ }^{26-28}$ The restriction of the multivariate analysis to 35-43 weeks of gestation was carried out to minimise possible bias resulting from high rates of patient transfer at gestational ages remote from term, and to provide a comparison group of physician delivered births that would be more similar to the types of cases midwives typically handle.

A sample of births was used for the multivariate analysis, as it is impractical and costly (in terms of computer processing time) to perform a multivariate regression analysis on all 4.1 million birth records given that this large a data set is not needed to explore the required statistical relations. Thus a smaller data set was created which included $100 \%$ of the eligible certified nurse midwife delivered births (153 194), together with a $25 \%$ random sample of physician delivered births (686 644). 
VARIABLES

The dependent variables in this study were infant, neonatal, and postneonatal mortality, low birthweight, and mean birthweight. Differences in these five dependent variables were modelled as functions of sociodemographic, health, and medical risk factors and complications. Sociodemographic and health risk factors examined included birth attendant, maternal age, race, education, marital status, birth order, month of pregnancy prenatal care began, and gestational age. Medical risk factors and complications refer to a number of new checkbox items added to the US birth certificate in 1989, eliciting information on medical risk factors of the pregnancy and complications of labour or delivery, or both. Only those risk factors that had a statistically significant effect on birth outcomes were included in the models. Factors included were hydramnios/ oligohydramnios, abruptio placenta, breech/ malpresentation, fetal distress, precipitous labour ( $<3$ hours), premature rupture of membrane ( $>12$ hours), and seizures during labour. All variables were measured as categorical variables as shown in table 2 .

Data on birth attendant comes from the "Attendant's name and title" item from the birth certificate, and is designed to elicit the name and title of the person who actually delivered the baby. The person who provided the prenatal care may or may not be the same person, although in many instances they are one and the same. Under reporting of midwife attended births has also been found, particularly among midwives who work for physicians. About six per cent of certified nurse midwives who attended births reported that they were not listed as the birth attendant on the birth certificate. $^{29}$

All variables were reported by all US states except for maternal education and maternal smoking during pregnancy. In 1991, data on maternal educational attainment was reported for all areas except Upstate New York (excluding New York City) and Washington State. These two areas taken together comprised $5.8 \%$ of total US births. Data on maternal smoking during pregnancy was reported for all areas except California, Indiana, New York, and South Dakota (26.9\% of total US births). For educational attainment, separate multivariate analyses were conducted excluding the non-reporting states, and including all US states, but with missing values for maternal education coded to a separate covariate category. As the results from the two analyses were very similar, it was decided to include all US states in the final analysis. For the smoking variable, the per cent of records with unknown responses was deemed to be too high, and the variable was excluded from the final multivariate analyses, although it was included in preliminary analyses (data not shown). As the proportion of women who smoked during pregnancy was quite similar between the physician and certified nurse midwife groups, the exclusion of this variable from the final analysis did not significantly change the relations
KEY POINTS

- Adjusted infant and neonatal mortality odds ratios were lower for certified nurse midwife than for physician delivered births.

- The risk of low birthweight was lower, and mean birthweight was higher for certified nurse midwife than for physician delivered births.

- Differences between physicians and certified nurse midwives in prenatal, labour, and delivery care practices may explain in part the differential outcomes.

between birth attendant and birth outcomes shown below.

Although the quality of data reported on birth certificates is generally considered to be quite reliable, questions have been raised about data accuracy for a few specific variables. Although questions have been raised in the past about the quality of gestational age data from birth certificates, ${ }^{30}$ data quality has improved substantially since 1989 when a separate item on clinical estimate of gestation was added to the birth certificate, and a consistency check between period of gestation computed from the date of last menstrual period, period of gestation based on the clinical estimate, and birthweight was implemented. ${ }^{31}$ Because of these and other measures, the per cent of birth records with not stated gestational age fell from $4.3 \%$ in 1988 to $1.0 \%$ in $1991,^{32}$ and records with highly implausible values (that is, 20 weeks gestation and 4000 grams birthweight) have been either corrected or assigned to not stated. ${ }^{31}$ Any remaining inaccuracies are unlikely to be differentially reported by birth attendant.

Studies comparing the reporting of the checkbox items on medical risk factors and complications of labour/delivery to medical records have found substantial under reporting of these variables. ${ }^{33-35}$ However, all of these studies were conducted within the first year or two of the implementation of the new birth certificate, and some authors felt that reporting was likely to improve as medical personnel became more familiar with the new form. ${ }^{34}$ Still, some degree of under reporting of these items is likely in the current analysis. However, as the birth certificates for hospital deliveries, which comprise the vast majority of physician and certified nurse midwife births, are probably filled out by the same medical records staff regardless of birth attendant, there is no evidence to support the notion of substantial bias between physician and certified nurse midwife groups in completeness of reporting of these items.

STATISTICAL METHODS

Multivariate logistic regression was used to examine the risk of infant, neonatal, and postneonatal mortality and low birthweight for singleton, vaginal births at $35-43$ weeks gestation delivered by physicians and certified nurse 
midwives, while controlling for sociodemographic and medical risk factors. Ordinary least squares regression was used to examine birthweight differences for births delivered by physicians compared with certified nurse midwives, while controlling for the same sociodemographic, health and medical risk factors, and complications. The parameters in the logistic model were estimated by the maximum likelihood method using the LOGISTIC procedure; those in the ordinary least squares model were estimated using the REG procedure of SAS, Version 6.

For each of the five dependent variables, three sets of regression models are presented. Model 1 presents the unadjusted odds ratios for each of the predictors (including birth attendant). Model 2 shows the effect of birth attendant when race/ethnicity, maternal age, birth order, marital status, maternal education, prenatal care, and gestational age are included in the model. Model 3 shows the adjusted dif-

Table 2 Logistic regressions showing crude and adjusted differentials in risk of infant mortality between physician and certified nurse midwife delivered singleton, vaginal births 35-43 weeks gestation: United States, $1991(n=810$ 790)

\begin{tabular}{|c|c|c|c|c|c|c|}
\hline \multirow[b]{2}{*}{ Covariate } & \multicolumn{2}{|c|}{ Model 1† } & \multicolumn{2}{|l|}{ Model $2 \ddagger$} & \multicolumn{2}{|l|}{ Model 3S } \\
\hline & $O R$ & $95 \% C I$ & $O R$ & $95 \% C I$ & $O R$ & $95 \% C I$ \\
\hline \multicolumn{7}{|l|}{ Attendant at delivery } \\
\hline Physician & 1.00 & & 1.00 & & 1.00 & \\
\hline Certified nurse midwife & 0.87 & $(0.73,1.03)$ & $0.80^{\star}$ & $(0.67,0.95)$ & $0.81^{\star}$ & $(0.68,0.96)$ \\
\hline \multicolumn{7}{|l|}{ Race/ethnicity } \\
\hline Non-Hispanic White & 1.00 & & 1.00 & & 1.00 & \\
\hline Black & $1.71^{\star \star}$ & $(1.56,1.87)$ & $1.12^{\star}$ & $(1.01,1.24)$ & $1.13^{\star}$ & $(1.02,1.25)$ \\
\hline American Indian & $2.03^{\star \star}$ & $(1.58,2.60)$ & $1.54^{\star \star}$ & $(1.17,2.01)$ & $1.52^{\star \star}$ & $(1.16,1.99)$ \\
\hline Asian & 0.97 & $(0.78,1.20)$ & 0.92 & $(0.75,1.14)$ & 0.94 & $(0.76,1.16)$ \\
\hline Hispanic & 0.93 & $(0.83,1.04)$ & $0.67^{\star \star}$ & $(0.59,0.75)$ & $0.68^{\star \star}$ & $(0.61,0.77)$ \\
\hline \multicolumn{7}{|l|}{ Maternal age, (y) } \\
\hline$<20$ & $1.67^{\star \star}$ & $(1.53,1.84)$ & $1.33^{\star \star}$ & $(1.19,1.49)$ & $1.35^{\star \star}$ & $(1.21,1.51)$ \\
\hline $20-34$ & 1.00 & & 1.00 & & 1.00 & \\
\hline $35+$ & 0.90 & $(0.78,1.03)$ & 0.90 & $(0.78,1.04)$ & 0.89 & $(0.77,1.03)$ \\
\hline \multicolumn{7}{|l|}{ Live birth order } \\
\hline 1 & 0.75 & $(0.69,0.81)$ & $0.65^{\star \star}$ & $(0.60,0.71)$ & $0.65^{\star \star}$ & $(0.59,0.70)$ \\
\hline $2-3$ & 1.00 & & 1.00 & & 1.00 & \\
\hline $4+$ & $1.31^{\star \star}$ & $(1.17,1.45)$ & $1.19^{\star \star}$ & $(1.06,1.32)$ & $1.18^{\star \star}$ & $(1.06,1.32)$ \\
\hline Unknown & 1.18 & $(0.68,2.04)$ & 1.01 & $(0.58,1.74)$ & 1.00 & $(0.58,1.73)$ \\
\hline \multicolumn{7}{|l|}{ Marital Status } \\
\hline Married & 1.00 & & 1.00 & & 1.00 & \\
\hline Unmarried & $1.81^{\star \star}$ & $(1.68,1.95)$ & $1.32^{\star \star}$ & $(1.21,1.45)$ & $1.31^{\star \star}$ & $(1.20,1.44)$ \\
\hline \multicolumn{7}{|l|}{ Maternal education, (y) } \\
\hline $0-11$ & $1.48^{\star \star}$ & $(1.36,1.61)$ & $1.28^{\star \star}$ & $(1.16,1.41)$ & $1.28^{\star \star}$ & $(1.16,1.40)$ \\
\hline 12 & 1.00 & & 1.00 & & 1.00 & \\
\hline $13+$ & $0.63^{\star \star}$ & $(0.57,0.70)$ & $0.73^{\star \star}$ & $(0.66,0.81)$ & $0.73^{\star \star}$ & $(0.66,0.81)$ \\
\hline Unknown & $3.27^{\star \star}$ & $(1.20,1.74)$ & $1.42^{\star \star}$ & $(1.18,1.71)$ & $1.39^{\star \star}$ & $(1.15,1.67)$ \\
\hline \multicolumn{7}{|l|}{ Prenatal care began } \\
\hline Ist trimester & 1.00 & & 1.00 & & 1.00 & \\
\hline Late or no prenatal care & $1.66^{\star \star}$ & $(1.53,1.79)$ & $1.27^{\star \star}$ & $(1.17,1.38)$ & $1.26^{\star \star}$ & $(1.16,1.37)$ \\
\hline Unknown & $1.42^{\star \star}$ & $(1.19,1.70)$ & 1.34 & $(1.06,1.70)$ & $1.32^{\star}$ & $(1.04,1.67)$ \\
\hline \multicolumn{7}{|l|}{ Gestational age } \\
\hline $35-36$ weeks & $3.05^{\star \star}$ & $(2.74,3.40)$ & $2.61^{\star \star}$ & $(2.34,2.91)$ & $2.50^{\star \star}$ & $(2.23,2.79)$ \\
\hline $37-38$ weeks & $1.53^{\star \star}$ & $(1.40,1.67)$ & $1.45^{\star \star}$ & $(1.32,1.58)$ & $1.43^{\star \star}$ & $(1.31,1.56)$ \\
\hline 39-41 weeks & 1.00 & & 1.00 & & 1.00 & \\
\hline $42-43$ weeks & $1.24^{\star \star}$ & $(1.09,1.42)$ & $1.16^{\star}$ & $(1.01,1.33)$ & 1.15 & $(1.00,1.32)$ \\
\hline Hydramnios/oligohydramn & & & & & & \\
\hline No & 1.00 & & & & 1.00 & \\
\hline Yes & $5.99^{\star \star}$ & $(4.74,7.56)$ & & & $5.07^{\star \star}$ & $(4.00,6.43)$ \\
\hline Unknown & 0.99 & $(0.84,1.16)$ & & & 1.02 & $(0.85,1.21)$ \\
\hline Abruptio placenta & & & & & & \\
\hline No & 1.00 & & & & 1.00 & \\
\hline Yes & $4.05^{\star \star}$ & $(2.76,5.94)$ & & & $2.83^{\star \star}$ & $(1.92,4.17)$ \\
\hline Unknown & 1.15 & $(0.86,1.54)$ & & & 1.19 & $(0.84,1.68)$ \\
\hline Breech/malpresentation & & & & & & \\
\hline No & 1.00 & & & & 1.00 & \\
\hline Yes & $3.50^{\star \star}$ & $(2.64,4.64)$ & & & $3.21^{\star \star}$ & $(2.42,4.25) \rrbracket$ \\
\hline Unknown & 1.15 & $(0.86,1.55)$ & & & & \\
\hline Fetal distress & & & & & & \\
\hline No & 1.00 & & & & 1.00 & \\
\hline Yes & $1.69^{\star \star}$ & $(1.37,2.07)$ & & & $1.59^{\star \star}$ & $(1.29,1.96)$ \\
\hline Unknown & 0.99 & $(0.86,1.13)$ & & & 1.00 & $(0.85,1.17)$ \\
\hline Precipitous labour $(<3$ hou & & & & & & \\
\hline No & 1.00 & & & & 1.00 & \\
\hline Yes & $1.52^{\star \star}$ & $(1.24,1.86)$ & & & 1.25 & $(1.02,1.54)$ \\
\hline Unknown & 1.15 & $(0.86,1.55)$ & & & & \\
\hline Premature rupture of mem & & & & & & \\
\hline No & 1.00 & & & & 1.00 & \\
\hline Yes & $1.50^{\star \star}$ & $(1.23,1.82)$ & & & 1.28 * & $(1.05,1.57)$ \\
\hline Unknown & 1.15 & $(0.86,1.55)$ & & & & \\
\hline Seizures during labour & & & & & & \\
\hline No & 1.00 & & & & 1.00 & \\
\hline Yes & $5.06^{\star \star}$ & $(1.75,14.58)$ & & & $4.65^{\star \star}$ & $(1.61,13.48) \rrbracket$ \\
\hline Unknown & 1.14 & & & & & \\
\hline Model $\chi^{2}$ & & & $1013.34^{\star \star}$ & & $1238.81^{\star \star}$ & \\
\hline $\mathrm{df}$ & & & 19 & & 29 & \\
\hline
\end{tabular}

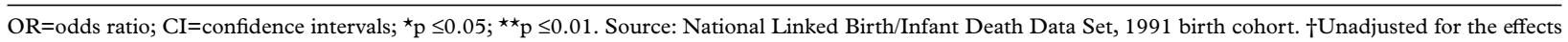
of other covariates. $¥$ Adjusted for the effects of attendant at delivery, maternal age, race/ethnicity, marital status, education, live birth order, prenatal care, and gestation. §Adjusted for the effects of attendant at delivery, maternal age, race/ethnicity, marital status, education, live birth order, prenatal care, gestation, and medical risk factors. TThe unknown categories for breech/malpresentation, meconium moderate/heavy, precipitous labour, premature rupture of membrane, and seizures during labour were a linear combination of the unknown category for abruptio placenta and were set to 0 in Model 3. 
ferentials in outcomes between physician and certified nurse midwife delivered births, when the medical risk factors and complications are included in addition to all of the covariates included in Model 2.

\section{Results}

Table 1 shows the characteristics of US births by attendant at delivery. Overall, $94.7 \%$ of US births in 1991 were delivered by physicians, $4.1 \%$ by certified nurse midwives, $0.4 \%$ by other midwives, and $0.8 \%$ by other and unknown attendants. Certified nurse midwives delivered $94.3 \%$ of their births in hospital compared with $99.7 \%$ for physicians. The infant mortality rate was $53.4 \%$ lower for births delivered by certified nurse midwives than for births delivered by physicians, although this differential was reduced to $13.9 \%$ when the analysis was restricted to singleton, vaginal deliveries at 35-43 weeks of gestation. This subgroup included $67.7 \%$ of the physician attended births and $91.3 \%$ of the midwife delivered births in the US.

The per cent of low birthweight and preterm births was substantially higher for physician than for certified nurse midwife deliveries although the difference was greatly reduced when only singleton vaginal deliveries at 35-43 weeks of gestation were examined. For this subgroup, mean birthweight was 26 grams higher, and mean gestational age 0.1 week longer for certified nurse midwife than for physician deliveries.

When the sociodemographic characteristics of births are examined, a greater percentage of certified nurse midwife than physician deliveries involve mothers who are at increased risk for poor birth outcomes. A higher proportion of the certified nurse nidwife deliveries occur among black women, American Indians, teenagers, women with three or more previous births, unmarried women, those with less than a high school education, and those with late or no prenatal care. Certified nurse midwives also attended a higher percentage of births to Hispanic origin mothers than did physicians. These mothers generally have relatively good outcomes despite a higher prevalence of sociodemographic risk factors. ${ }^{36} 37$

When the medical risk profile of physician and certified nurse midwife delivered births was examined, physicians attended more births with abruptio placenta, breech/malpresentation, fetal distress and hydramnios/oligohydramnios, while certified nurse midwives attended more women with precipitous labour and premature rupture of membrane. However, these differentials were greatly reduced when the analysis was restricted to singleton, vaginal deliveries 35-43 weeks of gestation. For this group, physicians attended a slightly higher proportion of births with abruptio placenta, breech/malpresentation, and fetal distress, while certified nurse midwives attended a slightly higher percentage of births with precipitous labour, and premature rupture of membranes.
DIFFERENTIALS IN INFANT MORTALITY

Table 2 shows the results of logistic regression analyses examining the effect of birth attendant and other covariates on infant mortality. In Model 1 the unadjusted risk of infant mortality was $13 \%$ lower for births delivered by certified nurse midwives than for births delivered by physicians. However, when the sociodemographic variables were controlled for in Model 2 , the difference in infant mortality risk between physician and certified nurse midwife deliveries actually increased to $20 \%$ (that is, the risk of infant mortality was $20 \%$ lower for certified nurse midwife delivered births). This probably relates to the higher sociodemographic risk profile of the certified nurse midwife attended group (see table 1). In Model 3 , this differential between certified nurse midwife and physician infant mortality risk was reduced to $19 \%$, reflecting the slightly higher medical risk profile of physician attended births.

At the suggestion of an anonymous reviewer, an additional model was computed with terms for very low birthweight $(<1500 \mathrm{~g})$ and moderately low birthweight (1500-2499 g) substituted for the period of gestation terms in table 2-Model 3. Results were similar to those shown in table 2-Model 3 (odds ratio $=0.83,95 \%$ confidence intervals $=0.70,0.98)$. As period of gestation is conceptually antecedent to birthweight, and as the models yielded similar results, the model shown in table 2 was retained in the final analysis.

When the effects of the other covariates on infant mortality were examined, the following characteristics were associated with increased risk of infant mortality in both unadjusted and adjusted models: black or American Indian race, teenage pregnancy, fourth or higher order births, non-marital childbearing, maternal education $<12$ years, late or no prenatal care, gestational age <39 weeks, hydramnios/oligohydramnios, abruptio placenta, breech/ malpresentation, fetal distress, precipitous labour, premature rupture of membrane, and seizures during labour. The increased risk of infant mortality associated with several of these variables was reduced substantially in Models 2 and 3 because of the combined effects of attendant and the other covariates. Gestational age of 42-43 weeks was associated with an increased risk of infant mortality in Model 1, but became statistically insignificant after other covariates were controlled in Model 3.

The unadjusted risk of infant mortality for Hispanic origin mothers was not initially different from that for white mothers. However, after covariates were adjusted in Models 2 and 3, the risk of infant mortality was about one third lower for Hispanic origin mothers. This is consistent with the empirical literature that reports favourable birth outcomes for Hispanic-Americans despite an increased prevalence of sociodemographic risk factors. ${ }^{3637}$ Characteristics associated with a reduced risk of infant mortality in both unadjusted and adjusted models included primiparity, and maternal educational attainment of 13 years or more. 
Table 3 Unadjusted and adjusted risks of adverse birth outcomes between physician and certified nurse midwife (CNM) delivered singleton, vaginal births 35-43 weeks gestation: United States, 1991

\begin{tabular}{|c|c|c|c|c|c|c|}
\hline & \multicolumn{2}{|l|}{ Model $1+$} & \multicolumn{2}{|l|}{ Model $2 \ddagger$} & \multicolumn{2}{|l|}{ Model 35 } \\
\hline & $O R$ & $95 \% C I$ & $O R$ & $95 \% C I$ & $O R$ & $95 \% C I$ \\
\hline \multicolumn{7}{|c|}{ Infant mortality (logistic regression) } \\
\hline Physician & 1.00 & & 1.00 & & 1.00 & \\
\hline CNM & 0.87 & $(0.73,1.03)$ & $0.80^{\star}$ & $(0.67,0.95)$ & $0.81^{\star}$ & $(0.68,0.96)$ \\
\hline \multicolumn{7}{|c|}{ Neonatal mortality (logistic regression) } \\
\hline Physician & 1.00 & & 1.00 & & 1.00 & \\
\hline CNM & $0.68^{\star}$ & $(0.49,0.95)$ & $0.66^{\star}$ & $(0.47,0.93)$ & $0.67^{\star}$ & $(0.48,0.94)$ \\
\hline \multicolumn{7}{|c|}{ Postneonatal mortality (logistic regression) } \\
\hline Physician & 1.00 & & 1.00 & & 1.00 & \\
\hline CNM & 0.95 & $(0.78,1.16)$ & 0.86 & $(0.71,1.05)$ & 0.86 & $(0.71,1.05)$ \\
\hline \multicolumn{7}{|c|}{ Low birthweight (logistic regression) } \\
\hline Physician & 1.00 & & 1.00 & & 1.00 & \\
\hline CNM & $0.71^{\star \star}$ & $(0.67,0.76)$ & $0.69^{\star \star}$ & $(0.65,0.74)$ & $0.69^{\star \star}$ & $(0.65,0.73)$ \\
\hline Mean birthweight (OLS & $\begin{array}{l}\text { B } \\
\text { ession) }\end{array}$ & $\mathrm{SE}(\mathrm{B})$ & B & $\operatorname{SE}(B)$ & B & $\mathrm{SE}(\mathrm{B})$ \\
\hline $\begin{array}{l}\text { CNM } \\
\text { (Physician=reference) }\end{array}$ & $26.97^{\star \star}$ & 1.39 & $36.14^{\star \star}$ & 1.30 & $36.57^{\star \star}$ & 1.30 \\
\hline
\end{tabular}

$\mathrm{OR}=$ odds ratio; $\mathrm{CI}=$ confidence intervals; $\mathrm{B}=$ unstandardised regression coefficient; ${ }^{\star} \mathrm{p}<0.05 ;{ }^{\star \star} \mathrm{p}<0.01$. + Unadjusted for the effects of attendant at delivery, maternal age, race/ethnicity, marital status, education, parity, prenatal care, and gestation. ‡Adjusted for the effects of attendant at delivery, maternal age, race/ethnicity, marital status, education, parity, prenatal care, and gestation. $₫$ Adjusted for the effects of attendant at delivery, maternal age, race/ethnicity, marital status, education, parity, prenatal care, gestation, and medical risk factors/complications.

DIFFERENTIALS IN NEONATAL AND

POSTNEONATAL MORTALITY, LOW BIRTHWEIGHT, AND MEAN BIRTHWEIGHT

The first and second panels in table 3 examine neonatal and postneonatal mortality risks for physician and certified nurse midwife delivered births. As expected, the effect of attendant at delivery on birth outcome is more pronounced during the neonatal than the postneonatal period. In Model 1, the risk of neonatal mortality was $32 \%$ lower for births delivered by certified nurse midwife than for physician delivered births. This differential increased slightly to $33-34 \%$ when the various risk factors were controlled in Models 2 and 3. For postneonatal mortality, the unadjusted risk of 0.95 decreased to 0.86 in the adjusted models (see table 3), although the difference was not statistically significant in either model. The unadjusted risk of delivering a low birthweight infant was $29 \%$ lower for certified nurse midwife than for physician delivered births. This differential increased slightly to $31 \%$ in Models 2 and 3.

Table 3 also includes the results of ordinary least squares regressions examining the effects of birth attendant and other covariates on mean birthweight. In Model 1, the mean birthweight was 27 grams higher for certified nurse midwife delivered than for physician delivered births. This differential in mean birthweight increased to 36 grams in Model 2, and to 37 grams in Model 3.

\section{Discussion}

Many studies have reported excellent birth outcomes for births delivered by midwives compared with physician delivered births. Many of these studies have shown the results for particular hospitals or birthing centres ${ }^{10-12} 14-1638$ while others have covered a wider geographical region. ${ }^{213}{ }^{18-2128}$ However, this is the first study known to us that examines mortality risks for all certified nurse midwife delivered births in the United States. For singleton, vaginal births at 35-43 weeks of gestation, the adjusted risk of infant mortality was $19 \%$ lower for certified nurse midwife than for physician attended births, the risk of neonatal mortality was 33\% lower, and the risk of delivering a low birthweight infant was $31 \%$ lower. Mean birthweight was 37 grams higher for certified nurse midwife than for physician attended births. Differences in postneonatal mortality were not statistically significant.

STRENGTHS AND LIMITATIONS OF THE STUDY Strengths of this study include the comprehensive population based nature of the data set, which includes all births in the United States in 1991, and the large number of sociodemographic and medical risk factors examined. Limitations include the cross sectional nature of the data set, which provides information on the attendant who actually delivered the baby, but not a complete history of prenatal care and labour and delivery care providers. For the certified nurse midwife births it is probable that a midwife also provided much or all of the prenatal care, as transfers from physician to midwife care are rare. However, patients might be transferred from midwife to physician care during prenatal care or during labour if the midwife felt that the woman's medical condition necessitated a physician's care. The single datum available on birth attendant also fails to take into account the possibility of copractice or joint case management of births between physicians and certified nurse midwives. Although the vast majority of physicians who deliver babies are engaged in physician only practices, ${ }^{39}$ a substantial minority of midwives are engaged in copractice with physicians. ${ }^{29}$ In these cases it may be the involvement of the midwife, with her excellent patient education and emotional support, ${ }^{2121316}$ which is important to better outcomes, rather than whether that involvement is exclusive of all other care providers. Still, the inability to account for the entire history of care providers has the potential to create bias in the comparison of 
birth outcomes between physician and certified nurse midwife groups.

Where possible, steps were taken to reduce the potential bias because of this lack of data. Besides statistical controls for many variables associated with patient transfer, the main step was to restrict the multivariate analysis to singleton, vaginal deliveries at 35-43 weeks of gestation, because rates of patient transfer are higher for multiple pregnancies and women delivering substantially before or after term. ${ }^{1626-28}$ The exclusion of caesarean births from the sample also helps to reduce potential bias, because a high proportion of patients transferred from midwifery to physician care undergo caesarean section. ${ }^{28}$ Although steps were taken where possible to minimise potential bias, some degree of bias may still be present, and may in part account for the differences in birth outcomes found in this study. It is reassuring to note, however, that many of the hospital or clinic-based studies in the literature were able to attribute outcomes for transferred patients to the attendant who provided the prenatal care, and still reported birth outcomes for certified nurse midwives that were as good as or better than those for physicians. ${ }^{11} 14283840-42$

\section{PRACTICE DIFFERENCES}

Data limitations notwithstanding, there are also real differences in the approach to patient care between certified nurse midwives and physicians that might also help to explain the differences in birth outcomes found in this study. These can be divided into two areas: those relating to the provision of prenatal care services, and those relating to labour and delivery practices, although differences in prenatal care practices cannot account for the differences in birth outcomes for the $1.7 \%$ of physician attended and $2.0 \%$ of midwife attended births with no prenatal care.

As regards prenatal care, certified nurse midwives generally spend more time with patients during prenatal visits, and put more emphasis on patient counselling and education, establishing trust, and providing emotional support and empowerment to the pregnant woman. ${ }^{2} 121316{ }^{43-45}$ Although time use data on prenatal care are sparse, a recent small scale study found that certified nurse midwives spent an average of 49.3 minutes for an initial visit, and 29.3 minutes for return visits, compared with 29.8 and 14.6 minutes, respectively, for physicians. ${ }^{45}$ A substantial portion of the increased time spent by nurse midwives in prenatal visits relates to patient counselling and education, as demonstrated in a study by Sculphome et al in which certified nurse midwives spent an average of eight minutes per visit on patient counselling and education, nine minutes on history and physical, six minutes on record review and charting, and 0.5 minutes on consultation. ${ }^{44}$

Recent studies have increasingly questioned the effectiveness of a purely biomedical model of prenatal care as a series of laboratory tests and interventions given at specified weeks of gestation. ${ }^{84}$ More important components of prenatal care seem to be lifestyle and behav- ioural advice, education about the birthing process, and emotional support. ${ }^{8446-48} \mathrm{~A}$ recent study on the relation of the content of prenatal care to the risk of low birthweight found that women who did not receive adequate prenatal advice and counselling were at an increased risk of delivering a low birthweight infant, but that no increased risk was associated with women who did not receive all of the recommended prenatal care procedures. ${ }^{47}$ In the results of an exhaustive literature review, the Office of Technology Assessment of the US Congress concluded that "Certified nurse midwives are more adept than physicians at providing services that depend on communication with patients and preventive actions." ${ }^{43}$ Another recent study on the content of prenatal care demonstrated that while all types of providers adhered closely to American College of Obstetricians and Gynecologists (ACOG) guidelines for the content of prenatal care visits, certified nurse midwives adhered most closely to the guidelines. ${ }^{49}$

Certified nurse midwives more often than physicians foster a more personalised approach to labour and delivery including encouraging women to ambulate during labour, encouraging alternative positions for delivery, allowing for intermittent rather than continuous fetal monitoring (necessary to allow for ambulation during labour), allowing food and drink during labour, and allowing women to deliver in a more relaxed non-clinical environment with the presence of family and friends. ${ }^{210} 16 \mathrm{An}$ integral part of nurse midwifery care is providing emotional support and empowerment to women in labour and a personalised approach to the labour and delivery process that allows the woman to choose the type of experience she will have. ${ }^{12}{ }^{13}$ During labour and delivery, most certified nurse midwives are with their patients on a one on one basis during the entire labour and delivery process, in contrast with physician's care, which is more often episodic. ${ }^{24}$ Studies have reported improved birth outcomes for women who received continuous emotional support during labour, including lower caesarean section rates, shorter durations of labour, and lower rates of anaesthesia and oxytocin use. ${ }^{48}$ 50-52 Although biochemical mechanisms are not entirely clear, studies have reported an association between maternal anxiety and decreased uterine contractility and decreased uterine and placental blood flow. ${ }^{50}$ Individualised care, better patient rapport and emotional support, and more time spent in prenatal counselling may help to explain in part the better outcomes for certified nurse midwife than physician births found in this study.

In conclusion, although significant gaps in data availability at the national level do exist, national data do support the findings of other local studies that certified nurse midwives have excellent birth outcomes, and provide a safe and viable alternative to maternity care in the United States, particularly for low and moderate risk women.

Funding: National Center for Health Statistics. Conflicts of interest: none. 
1 National Center for Health Statistics. Health United States, 1995. Hyattsville, Maryland: Public Health Service, 1996. 1995 . Hyattsville, Maryland: Public Health Service, 1996.
Public Citizen's Health Research Group. Encouraging the use of nurse midwives. Washington DC: Public Citizen's Health of nurse midwives. Wash

3 The Alan Guttmacher Institute. Blessed events and the bottom line: financing maternity care in the United States. New York: The Alan Guttmacher Institute. 1987.

4 Institute of Medicine, National Academy of Sciences. Preventing low birthweight. Washington: National Academy Press, 1985.

5 Institute of Medicine, National Academy of Sciences. Prenatal care: reaching mothers, reaching infants. Washington: National Academy Press, 1988.

6 National Center for Health Statistics. Advance Report of Final Natality Statistics, 1991. Mom hy vital statistics report vol 42 no 3 , sup

7 Ventura SJ, Martin JA, Mathews TJ, et al. Advance Report of Final Natality Statistics, 1994. Monthly vital statistics of Final Natality Statistics, 1994. Monthly vital statistics report; vol 44 no 11 suppl. Hyattsville,

8 Rosenblatt RA. The perinatal paradox: Doing more and accomplishing less. Health Affairs 1989;8:158-68.

9 National Commission to Prevent Infant Mortality. Troubling trends persist: shortchanging America's next generation. Washington DC: National Commission to Prevent Infant Mortality, March 1992

10 Strobino DM, Baruffi G, Dellinger, WS, et al. Variations in pregnancy outcomes and use of obstetric procedures in two institutions with divergent philosophies of maternity care. Med Care 1988;26:333-47.

11 Hueston WJ, Rudy M. A comparison of labor and delivery management between nurse midwives and family physicians. F Fam Pract 1993;37:449-54.

12 Butler J, Abrams B, Parker J, et al. Supportive nurse-midwife care is associated with a reduced incidence of cesarean section. Am f Obstet Gynecol 1993;168:1407-13.

13 Rooks JP, Weatherby NL, Ernst EKM, et al. Outcomes of care in birth centers: The national birth center study. $N$ care in birth centers: The nation

14 Davis LG, Riedman GL, Sapiro M, et al. Cesarean section rates in low-risk private patients managed by certified nurse-midwives and obstetricians. F Nurse Midwifery 1994 39:91-7.

15 Schimmel LM, Lee KA, Benner PE, et al. A comparison of outcomes between joint and physician-only obstetric practices. Birth 1994;21:197-204.

16 Greulich B, Paine LL, McClain C, et al. Twelve years and more than 30,000 nurse midwife attended births: The Los Angeles County-University of Southern California Women's Hospital Birth Center experience. $\mathcal{F}$ Nurse Midwifery 1994;39:185-96.

17 Knedle-Murray ME, Oakley DJ, Wheeler JR, et al . Production process substitution in maternity care: Issues of cost, quality, and outcomes by nurse-midwives and physician providers. Medical Care Review 1993;50:81-112.

18 Taffel S. Midwife and out-of-hospital deliveries, United States. Vital Health Stat Series 21 No. 40. Hyattsville, States. Vital Health Stat Series 21 No. 40. Hyattsville,

19 Declercq ER. The transformation of American midwifery: 1975 to 1988 . Am f Public Health 1992;82:680-4.

20 Declercq ER. Midwifery care and medical complications: the role of risk screening. Birth 1995;22:68-73.

21 Declercq ER. Where babies are born and who attends their births: findings from the revised 1989 United States Standard Certificate of Birth. Obstet Gynecol 1993;81:997-1004

22 Parker JD. Ethnic differences in midwife-attended US births. Am $\mathcal{F}$ Public Health 1994;84:1139-41.

23 Sculpholme A, De Joseph JF, Strobino DM, et al. Nurse-midwifery care to vulnerable populations phase I: Demographic characteristics of the national CNM sample. f Nurse Midwifery 1992;37:341-7.

24 Butter IH, Kay BJ. State laws and the practice of lay midwifery. Am f Public Health 1988;78:1161-9.

25 National Center for Health Statistics. Linked Birth/Infant Death Data Set: 1991 Birth Cohort, Public Use Data Tape Death Data Set: 1991 Birth Cohort, Public Use Data Tape
Documentation. Hyattsville, MD: Public Health Service, Docum
1991.

26 El Halta V. Too small, too soon. Midwifery Today 1995;36:35-7.

27 Edmunds J. Premature babes. Midwifery Today 1995;36:334 .
28 Rooks JP, Weatherby NL, and Ernst EK. The National Birth Center study, part III- Intrapartum and immediate postpartum and neonatal complications and transfers, postpartum and neonatal care, outcomes, and client satisfaction. $\mathcal{F}$ Nurse Midwifery 1992,37:361-97.

29 Walsh LV, Boggess JH. Findings of the American College of Nurse-Midwives Annual Membership Surveys, 1993 and 1994. F Nurse Midwifery 1996;41:230-5.

30 David RJ. The quality and completeness of birthweight and gestational age data in computerized birth files. Am $\mathcal{F ~ P u b -}$ lic Health 1980;70:964-73.

31 National Center for Health Statistics. Instruction Manual Part 12: Computer Edits for Natality Data. Hyattsville, Maryland: Public Health Service, 1995.

32 National Center for Health Statistics. Vital Statistics of the United States, Vol. I, Natality. Washington: Public Health Service (published annually)

33 Buescher PA, Taylor KP, Davis MH, et al. The quality of the new birth certificate data: A validation study in North Carolina. Am f Public Health 1993;83:1163-5.

34 Piper JM, Mitchel EF, Snowden M, et al. Validation of 1989 Tennessee birth certificates using maternal and newborn hospital records. Am f Epidemiol 1993;137:758-68.

35 O'Reilly MP, A birth certificate audit program in Pennsylvania. In: Proceedings of the 1991 Public Health Conference on Records and Statistics. Hyattsville, Maryland: National Center for Health Statistics, 1992:57-62

36 Pastore LM, MacDorman MF. Infant mortality by Hispanic origin of mother, 20 states, 1985-87 birth cohorts. Vital Health Stat 20(27). Hyattsville, Maryland: National Center for Health Statistics, 1995.

37 Becerra JE, Hogue CJR, Atrash HK, et al. Infant mortality among Hispanics; a portrait of heterogeneity. $7 A M A 1991$; 265:217-21

38 Chambliss LR, Daly C, Medearis AL, et al. The role of selection bias in comparing cesarean birth rates between physician and midwifery management. Obstet Gynecol 1992;80:161-5.

39 American College of Obstetricians and Gynecologists. Profile of Ob-Gyn Practice, 1991-1994. Washington DC: ACOG occasional paper, 1996.

40 Rooks JP, Weatherby NL, Ernst EKM. The national birth center study, part I- Methodology and prenatal care and referrals. F Nurse Midwifery 1992;37:222-52.

41 Rooks JP, Weatherby NL, Ernst EKM. The national birth center study, part II- Intrapartum and immediate postpartum and neonatal care. F Nurse Midwifery 1992;37:301-29.

42 Turnbull D, Holmes A, Shields N, et al. Randomised, controlled trial of efficacy of midwife-managed care. Lancet 1996;348:213-18.

43 US Congress, Office of Technology Assessment. Nurse practitioners, physician assistants, and Certified Nurse-Midwives: A policy analysis. Health Technology Case Study 37, OTAHCS-37. Washington, DC: US Government Printing Office, 1986.

44 Sculpholme A, Paine LL, Lang JM, et al. Time associated with components of clinical services rendered by nursewith components of clinical services rende
midwives. F Nurse Midwifery, 1994;39:5-12.

45 Yankou D, Petersen BA, Oakley D, et al. Philosophy of care: A pilot study comparing Certified Nurse Midwives and physicians. F Nurse Midwifery 1993;38:159-64.

46 Buescher PA, Smith C, Holliday JL, et al. Source of prenatal care and infant birth weight: The case of a North Carolina county. Am F Obstet Gynecol. 1987;156:204-10.

47 Kogan MD, Alexander GR, Kotelchuck M, et al. Relation of the content of prenatal care to the risk of low birthweight. fAMA 1994;271:1340-5.

48 Miller CA. Maternal and infant care: Comparisons between Western Europe and the United States. Int 7 Health Serv 1993;23:655-64.

49 Baldwin LM, Raine T, Jenkins LD, et al. Do providers adhere to ACOG standards? The case of prenatal care. Obstet Gynecol 1994;84:549-56.

50 Kennell J, Klaus M, McGrath S, et al. Continuous emotional support during labor in a US hospital: A randomized controlled trial. $f A M A$ 1991;265:2197-201.

51 Sosa R, Kennell J, Klaus M, et al. Th effect of a supportive companion on perinatal problems, length of labor, and mother-infant interaction. N Engl f Med 1980;303:597600.

52 Klaus M, Kennell J, Robertson S, et al. Effects of social support during parturition on maternal and infant morbidity. BMF 1986;293:585-7. 